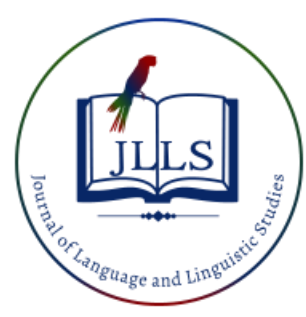

Available online at www.jlls.org

JOURNAL OF LANGUAGE

AND LINGUISTIC STUDIES

ISSN: $1305-578 \mathrm{X}$

Journal of Language and Linguistic Studies, 17(2), 1013-1022; 2021

\title{
Malaysian folktales: An understanding of the motif- index of folk literature applicability in the local folktales' context
}

\author{
Harryizman Harun a $^{\text {iD }, ~ A z l i z a ~ O t h m a n ~}{ }^{\text {b }}$ iD, Subashini Annamalai ${ }^{c}$ iD \\ ${ }^{\text {a.b,c }}$ School of Multimedia Technology and Communication, Universiti Utara Malaysia (UUM), Malaysia
}

\section{APA Citation:}

Harun, H., Othman, A., Annamalai, S. (2021). Malaysian folktales: An understanding of the motif- index of folk literature applicability in the local folktales' context. Journal of Language and Linguistic Studies, 17(2), 1013-1022. Doi: 10.52462/j1ls.70

Submission Date: 20/02/2021

Acceptance Date: 15/05/2021

\begin{abstract}
The motif of the folktale is essentially the smallest and striking elements of narrative content with the ability to endure in tradition. It is divided into three categories: actor, item and single incident. These categories become the foundation that supports the built of the original motif-index of folk literature by Stith Thompson. Nevertheless, the index, as an analysis tool, was developed based on an analysis conducted on mostly European folk literature (folktale inclusive). It is a question dawned on the researcher regarding the applicability of the universal motifs and sub-motifs listed in the index on Malaysian folktales considering such local folktales were not involved in the making of the index many moons ago. Therefore, the study seeks to understand the applicability of the original motif-index in the local folktales' context. The qualitative text analysis method was mainly employed in Atlas.ti, a computer-aided qualitative data analysis software (CAQDAS) to propel the study in understanding the scenario stated. Being the heart of the article, it is found that the original motif-index is indeed applicable in the local folktales' context to a certain extent. Inopportunely, not all the universal motifs from the index exist in the local folktales. The applicability and dispersion of the motif classes' weight which leans toward the D. Magic class, is heavily influenced by the differences between the local and the European cultures because truly what is folktale if not a fruit of a unique culture.
\end{abstract}

Keywords: Folktale's Motif; Malaysian Folktale; Qualitative Text Analysis; Motif-Index of Folk Literature; Motif Analysis Tool.

\section{Introduction}

Stith Thompson invented a classification of folk literature, among others folktale, legend, and myth based on the motif embedded deep in the content of such literature. The motif is the tiniest, peculiar and conspicuous element in a tale that encompasses three categories-actors, items, and single incidents (Thompson, 1977/1946). The third category of the motif is the one that covers most of the motifs and is capable of existing independently in its right as a tale. Believing that a sufficient classification of the motif is momentous in the study of tales, Thompson introduced an extensive list of motif-index with the purpose as an analysis tool to gather folk literature and to organise them logically. The list of main motifs identified, along with its brief explanation, is as shown in Table 1. The details of the sub-motifs

\footnotetext{
1 Corresponding author.

E-mail address: harry@uum.edu.my
} 
are not provided due to the sheer numbers of them.

Table 1. The Motif-Index of Folk-Literature (Main Motifs)

\begin{tabular}{|c|c|c|}
\hline$\overline{\text { Class }}$ & Motif & Explanation \\
\hline$\overline{\mathrm{A}}$ & Mythological & Creators and Godly motifs \\
\hline B & Animals & Animal substances \\
\hline $\mathrm{C}$ & Tabu & Forbidden things from many facets \\
\hline $\mathrm{D}$ & Magic & $\begin{array}{l}\text { Magical motifs such as object, power, and } \\
\text { transformation }\end{array}$ \\
\hline $\mathrm{E}$ & The Dead & The dead motifs such as ghost, soul, and reincarnation \\
\hline $\mathrm{F}$ & Marvels & $\begin{array}{l}\text { Wonders and miracle such as the journey to alternate } \\
\text { worlds, marvellous creatures, and places }\end{array}$ \\
\hline G & Ogres & $\begin{array}{l}\text { Motifs of horrible beings such as witches, trolls, and } \\
\text { devils }\end{array}$ \\
\hline $\mathrm{H}$ & Tests & $\begin{array}{l}\text { The trial in many forms such as identity, marriage, and } \\
\text { intelligence }\end{array}$ \\
\hline $\mathrm{J}$ & $\begin{array}{l}\text { The Wise and The } \\
\text { Foolish }\end{array}$ & $\begin{array}{l}\text { The mentality of a tale's character such as smart, } \\
\text { stupid, wise, or unwise }\end{array}$ \\
\hline $\mathrm{K}$ & Deceptions & $\begin{array}{l}\text { The deceptive action of characters such as thieving, } \\
\text { tricking and lying }\end{array}$ \\
\hline $\mathrm{L}$ & Reversal of Fortune & Turnaround of destiny \\
\hline M & $\begin{array}{l}\text { Ordaining the } \\
\text { Future }\end{array}$ & Predestined future and the action to avoid or foster it \\
\hline $\mathrm{N}$ & Chance and Fate & The role of luck in determining destiny and outcome \\
\hline $\mathrm{P}$ & Society & $\begin{array}{l}\text { Social order in a society that affects the rank, } \\
\text { profession, and management of law or army }\end{array}$ \\
\hline Q & $\begin{array}{l}\text { Rewards and } \\
\text { Punishments }\end{array}$ & $\begin{array}{l}\text { The consequences of action whether to be rewarded or } \\
\text { vice versa }\end{array}$ \\
\hline $\mathrm{R}$ & $\begin{array}{l}\text { Captives and } \\
\text { Fugitives }\end{array}$ & $\begin{array}{l}\text { Apprehension and escapism from captivation in the } \\
\text { light of action and character }\end{array}$ \\
\hline $\mathrm{S}$ & Unnatural Cruelty & $\begin{array}{l}\text { Inhuman atrocity acts such as persecution, castaway, } \\
\text { and abandonment }\end{array}$ \\
\hline $\mathrm{T}$ & Sex & $\begin{array}{l}\text { Sex motifs such as love, birth, pregnancy, lewdness } \\
\text { and many more }\end{array}$ \\
\hline $\mathrm{U}$ & The Nature of Life & $\begin{array}{l}\text { The essence of life such as justice and injustice, right } \\
\text { and wrong, and wealth and poverty }\end{array}$ \\
\hline V & Religion & $\begin{array}{l}\text { Religion-related motifs such as worship, heretic, mass, } \\
\text { and prayer }\end{array}$ \\
\hline $\mathrm{W}$ & Traits of Characters & $\begin{array}{l}\text { The features of characters such as kindness, bravery, } \\
\text { loyalty, and prudence }\end{array}$ \\
\hline $\mathrm{X}$ & Humor & $\begin{array}{l}\text { Various humor perspectives such as the corporeal } \\
\text { disability, social classes, and tradesmen }\end{array}$ \\
\hline $\mathrm{Z}$ & $\begin{array}{l}\text { Miscellaneous } \\
\text { Groups of Motifs }\end{array}$ & $\begin{array}{l}\text { Motifs that hardly able to stand on its own in an } \\
\text { individual chapter }\end{array}$ \\
\hline
\end{tabular}

Source: (Thompson, 1966) 
However, the 23 motif classes initially created (Thompson, 1966) was erected predominantly based on the analysis of European folk literature. It beckons a question whether the original motif-index applies to the Malaysian folktales. Do the motifs and sub-motifs extracted from the folktales of foreign culture exist in the local folktales that laden with the distinct culture? In order to untangle the perplexity, the study endeavours to understand the applicability of the universal motifs and sub-motifs in the local folktales' context by utilising the original motif- index as the analysis tool. The article begins with the current section (the Introduction) follows by the background of the study. Then the methods that drove the study are elaborated entails by the offering of the findings in the Analysis and Result section. The interpretations of the findings are presented in the Discussion section, and the article rings the curtain down with the Conclusion and the Reference sections. The ensuing section clarifies the background of the study with some related works to reveal the gap of the present study.

\section{Background}

In the study of folklore, a motif is the tiniest component in the tale that can endure in tradition. For a component to be a motif, it must possess something prominent that sets it apart from the rest of the general component in the tale. There are three categories of a motif, as presented in Table 2, along with examples for each category.

Table 2. The Three Categories of the Motif

\begin{tabular}{ll}
\hline Motif Category & Example \\
\hline \multirow{3}{*}{ Actor } & $\begin{array}{l}\text { Cruel stepmother Youngest tortured child } \\
\text { The most beautiful princess }\end{array}$ \\
& $\begin{array}{l}\text { Magical knife Odd puzzle } \\
\text { Talking helpful fish } \\
\text { Item }\end{array}$ \\
Maiden cursed by Moon \\
Single Incident & $\begin{array}{l}\text { Witch transfigures prince to the serpent } \\
\text { Evil parents abandon kids }\end{array}$ \\
& \\
\hline
\end{tabular}

Five previous studies that relate to the motif of folk literature, especially folktale, were reviewed in order to unveil the gap of the present study and the significance of the motif-based study in eclectic culture. The first study involves the creation of motif-index of Latvian folktales and legends (Neuland, 1981). The point of the motif-index was to provide access to the scholars internationally to study the Latvian folk literature and to reveal the undiscovered motifs native to the Latvian folktales and legends. Its core was built on the original motif-index of folk literature. The second study, which focuses on the motif-index of medieval Catalan folktales, resembles the first study in terms of its aim (Neugaard, 1993). Basing on the Thompson's motif-index of folk literature too, the purpose of the motif-index was to become a platform of investigation to international scholars to research on familiar and unfamiliar motifs of Catalan folktales to develop prose fiction in the Iberian Peninsula. The third study relates to the formation of motif-index of the Arab's folk narratives (El-Shamy, 1995a, 1995b). The study employed the original motif-index of folk literature too as the theoretical orientation that scaffolds the motif-index construction. The motif-index is meant to aid scholars in ascertaining traditional Arab culture motifs and utilise them in a broader sense of cultural and academic research environments. It was also triggered by the fact that the original motif-index does not lucidly represent the Arab-Islamic data, and its conception helps to expand the original motif- index by including the aspects of ArabIslamic culture and society.

The fourth study examined the folk narratives of Medieval Spanish to create a motif-index (Goldberg, 1998). Just the same with the previous studies reviewed, the original motif-index was 
exploited as the basis to identify motifs in the folktales examined. The study believes that the motifindex is crucial as it represents narrative units in an organised framework which allows recognition in familiars narrative components. It also uncovers that folktales' building blocks are migratory and disseminate in time and space. The fifth and last study analysed for the motifs embedded in the original Arabic folk literature of The Thousand and One Nights or famously known as Alf Laylah Wa Laylah (El-Shamy, 2006). The original motif-index of folk literature became the analysis tool to dissect and identify the motifs ingrained in the specific piece of Arabic folk literature. Fundamentally, the study aimed to bring justice to the original work of the folk literature considering many diluted editions followed the inception of the original work. Since the analysed data is momentous in the Arab culture, the study hopes that via the motif-index generated, the scholars of the humanities and social sciences would gain objective insight and understanding of The Thousand and One Nights.

Based on the five studies reviewed, it is evident that the motifs in general play a particularly crucial role in comprehending the composition of folk literature of any culture. The original motif-index, on the other hand, can never be denied of its contribution and significant function as the analysis tool to folk literature of various cultures. In addition, it is perceived that from the five past studies examined, none of them investigated the collection of Malaysian folktales. Also, it is realised that no such studies had been conducted on Malaysian folktales data in recent years. Deeming the critical contribution the motif study has on a particular nation's folklore, such a gap readies a platform for the current study to achieve precisely what the previous studies accomplished for the respective folk literature. By understanding the applicability of the motif-index in the local folktales' context, it opens up a possibility and prepares a tool for the international scholars to understand and academically exploit the motifs rooted in the local folktales. The ensuing section details the methodology of the study.

\section{Methodology}

The current section is divided into two subsections: the data collection and the motif analysis. The first subsection contains the units of analysis, the sampling technique and the sampling size. The second subsection encompasses the coding scheme and the analysis process. The next subsection elaborates the data collection methods.

\subsection{Data collection}

The collection of the Malaysian folktales preceded the motif analysis. In order to do that, units of analysis, and a sampling technique and size must be established. Three units of analysis were set in this study: sampling, coding, and context (Krippendorff, 2013; Miles, Huberman, \& Saldana, 2014; Schreier, 2012). The sampling technique used was relevance/purposive sampling and the folktales sampled was curbed to 269 Malay tales.

\section{Units of Analysis}

The sampling unit was the collection of Malaysian folktales itself in literary construct because it was the unit that subjects to be analysed. In this study, a coding unit was in the form of motif that embodies the content of the folktales collected. A coding unit is a derivation and part of a sampling unit. It represents the smallest units of information in the material to be analysed. Given these reasons, it is judicious that the motif represented the coding unit of the study. It is because the motif is the building block of a folktale in its distinctive way. Parallel to the research question of this study, the coding unit selected was part of the equation in understanding the original motif-index's applicability in the local folktales' context.

A context unit, on the other hand, is the wall that formulates the boundary on the information 
described by the coding unit to unravel meanings. It is uncountable and independent of each other, and it can overlap and may be referred to in describing several coding units. From the aspect of this study, the narratives in the folktales that surround the motifs became the context unit because to identify the motifs in the folktales, the narratives that carry the meaning must be understood first. The entailing subsection presents the sampling technique used in the study.

\section{Sampling Technique}

Concerning the sampling technique in appropriating the study with a manageable number of folktale literature, relevance/purposive sampling was elected. This sampling technique primarily investigates the chosen text to be analysed in order to answer specified research questions, and the method is considered suitable to sample heritage and storytelling body of work (Krippendorff, 2013; Laas, 2011; Whyte \& Classen, 2012). Due to the nature of this study, which deals with folktale and the research question that imposes on a story and culture-related matter, this technique was considered apt to be exploited. It requires relevance criteria to define the population of the sampling unit selected.

The relevance criteria of the sampling technique were instituted based on the operational definition of the folktales as erected by Bascom (1965). It was imperative to confirm that the folktales collected were in the form of the folklore required. It was due to the fine line separating the definition of diverse tales such as myth, legend, and folktale. This measure also determined the standardisation and consistency of the collected folktales. Each of the Malaysian folktales collected must be analysed and compared with five compulsory components in order for it to be deemed as a folktale and accepted to be involved as a part of the collection to be analysed in this study. If one of the components were absent, the folktale would be excluded from being a part of the collection. The five compulsory components of the folktale's definition are as in Table 3.

Table 3. The Five Compulsory Components of the Folktale's Definition

\begin{tabular}{ll}
\hline Component & Explanation \\
\hline Belief & The folktale is not a history or a fact but fiction. \\
Time & $\begin{array}{l}\text { The folktale does not have a specific remote and relatively recent } \\
\text { timeline, date, or year of occurrence. }\end{array}$ \\
& $\begin{array}{l}\text { The incident of the folktale that is not tied to any exact remote or relatively } \\
\text { recent locations in the tale. Even if locations do exist in the } \\
\text { tale, they are purely fictional. } \\
\text { Place }\end{array}$ \\
& $\begin{array}{l}\text { The folktale is also deemed as not containing any religious, ritual, or } \\
\text { sacred motivation. The most it can serve is amusement and moral value. }\end{array}$ \\
Attitude & $\begin{array}{l}\text { The folktales tell about the escapade and journey of human or non- human } \\
\text { characters. The human and non-human characters may come } \\
\text { Principal Character }\end{array}$ \\
& in many forms. \\
\end{tabular}

Source: (Bascom, 1965)

With the operational definition of the folktale established as the relevance criteria for the sampling unit (the Malaysian folktales collection), the sampling size was next determined.

\section{Sampling Size}

There are no rules on the number of tales collected, but the sampling size should permit the study to draw a valid conclusion of the study conducted (Jason, 2000; Propp, 1998). In past studies on folk literature such as "Type of the Latvian Folktales" and "The Comparative Index of Plots of East Slavic Folktale", the volume of the body of tales diverged between 120 to 67000 texts (Jason, 2000). The lack of rules in determining the size of folktale sample indicates that a minimum number of texts is vital in 
drawing a valid conclusion in a study.

In one study on Burmese folktales, the structural analysis involved a collection of twenty-seven folktales yet produced a sound finding (Lwin, 2010). Propp (1998) reinforced this perception by postulating that it is unnecessary to analyse all existing folktales because the gathering of folktales can be suspended once a new pattern is no longer presented. One-hundred tales are more than sufficient to be collected in a study because the quality of the tales collected transcends the value of the quantity (Propp, 1998). Baughman (1966) added that for folktale research to be published, the collection task should stop at some point and focus on the ones that are already accumulated. Hence in deciding the sampling size in this study, the number of folktales analysed in identifying the motif was kept to 269 Malay folktales. The following Table 4 summarises the data collection method of this study. The next section elucidates the method to analyse the motif in the folktales selected.

Table 4. The Data Collection Method

\begin{tabular}{lll}
\hline & \multicolumn{1}{l}{ Data Collection Method } \\
\hline Sampling Technique & $:$ & $\begin{array}{l}\text { Relevance/Purposive } \\
\text { Sampling Unit }\end{array}$ \\
Coding Unit & $:$ & $\begin{array}{l}\text { The collection of Malaysian folktales based on the relevance } \\
\text { criteria (the operational definition of the } \\
\text { folktale in this study) }\end{array}$ \\
Context Unit & $:$ & Motif \\
\hline
\end{tabular}

\subsection{Motif Analysis}

The chosen folktales as sampling unit were analysed via qualitative text analysis (QTA) method considering the literary construct of the data (Kuckartz, 2014; Schreier, 2013). The QTA method was implemented in the ecosystem of Atlas.ti to augment the validity and credibility of the analysis by rendering it more transparent, systematic, and replicable (Friese, 2019; Hwang, 2008). There are five levels to the QTA method, which were adapted to the extant study.

It commenced with the careful reading and interpretation of the individual folktale data to broadly identify the motifs in the folktales as the unit of coding. The context unit assisted in the identification endeavour. Subsequently, a codebook was built on two levels. The first level was made of the three categories of the motif, as presented in Table 2. Underneath each category, examples of the categories of motifs were fashioned to further support the context unit in the identification of the motifs. The universal motifs from the original motif-index formed the second level. A residual category was necessary in case of emergence of new motifs that were not found in the original motif- index. However, since the original motif-index has prepared the class Z. Miscellaneous Groups of Motifs for motifs that are not significant enough to stand on its own, that particular motif class became the residual category to contain any motifs from the local folktales that did not apply to the rest of the motif classes. With the codebook built as the coding scheme, the folktales were segmented based on the categories of motifs. The segments were then further coded using the universal motifs to identify the motifs that were applicable in the local folktales' context. Through the entire coding process, the universal motifs were gradually reduced to fit the context of the Malaysian folktales analysed. Once coded, the codes tagged to the segments were analysed to ascertain the answers to the inquiry that inspired the study. The last level was to present the results of the analysis to understand the applicability of the universal motifs from the original motif-index on the local folktales. The following section delivers the results of the analysis executed. 


\section{Analysis and Result}

Based on the analysis executed on the 269 local folktales, it is exposed that only twenty-two out of the twenty-three classes of the original motif-index apply to the Malaysian folktales in the setting on the current study. The one class that is not applicable is class V: Religion because its description does not match the fourth established relevance criteria of the sampling technique in this study: attitude. As for the motifs and sub-motifs for each of the applicable classes, there is an apparent reduction in number compared to the original motif-index. It is the consequence of adapting the original motif-index to the Malaysian folktales, which are loaded with unique culture compared to the European tales. Table 5 compares the number of Malaysian folktales' motifs acquired with the universal motifs in descending order. The next section encompasses the discussion of the study.

Table 5. The Number of Malaysian Folktale's Motifs and the Universal Motifs

\begin{tabular}{|c|c|c|c|c|}
\hline \multicolumn{5}{|c|}{ Number } \\
\hline & \multirow[b]{2}{*}{ Motif Class } & \multicolumn{2}{|c|}{ Malaysian Folktale'sUniversal } & \multirow[t]{2}{*}{ Sub- } \\
\hline & & Sub- Motif & Motif & \\
\hline $\mathrm{D}$ & Magic & 486 & 7189 & \\
\hline B & Animals & 374 & 2684 & \\
\hline $\mathrm{F}$ & Marvels & 327 & 5375 & \\
\hline A & Mythological & 306 & 5844 & \\
\hline $\mathrm{H}$ & Tests & 240 & 2778 & \\
\hline $\mathrm{J}$ & The Wise and The Foolish & 191 & 3564 & \\
\hline $\mathrm{K}$ & Deceptions & 173 & 3888 & \\
\hline Q & Rewards and Punishments & 170 & 1515 & \\
\hline $\mathrm{P}$ & Society & 113 & 858 & \\
\hline $\mathrm{C}$ & Tabu & 100 & 1217 & \\
\hline $\mathrm{N}$ & Chance and Fate & 88 & 1022 & \\
\hline $\mathrm{T}$ & Sex & 80 & 1507 & \\
\hline $\mathrm{L}$ & Reversal of Fortune & 74 & 322 & \\
\hline M & Ordaining the Future & 70 & 856 & \\
\hline G & Ogres & 68 & 1755 & \\
\hline $\mathrm{R}$ & Captives and Fugitives & 68 & 513 & \\
\hline $\mathrm{W}$ & Traits of Character & 61 & 371 & \\
\hline $\mathrm{S}$ & Unnatural Cruelty & 55 & 538 & \\
\hline $\mathrm{Z}$ & Miscellaneous Groups of Motifs & 46 & 450 & \\
\hline $\mathrm{X}$ & Humor & 44 & 772 & \\
\hline $\mathrm{E}$ & The Dead & 28 & 2227 & \\
\hline $\mathrm{U}$ & The Nature of Life & 16 & 171 & \\
\hline & Total & 3178 & 45416 & \\
\hline
\end{tabular}

\section{Discussion}

From Table 5, a closer inspection at the sub-motifs which emerged from the analysis shows the dominance in the applicability of the universal motifs on the local folktales even though the massive reduction is apparent from the applicability aspect. It speaks volume regarding the transference and migration of folktale motifs of diverse cultures. Since the motif classes are arranged in descending order, it can be seen that the sub-motifs applicable the most is from the class of D. Magic, and the least applicable is the $U$. The Nature of Life. The dominance indicates that in the sub-motifs that relate to 
magical matters such as an object, power and transformation, the transference and migration of motifs from the European to the local folktales is resilient. The same cannot be said about the sub-motifs that concern with the essence of life, for instance, justice and injustice, right and wrong, and wealth and poverty. It is discovered that the 486 sub- motifs of magic permeate twenty-six local folktales out of 269 analysed and the 16 sub-motifs of the nature of life five. It denotes that the same motif may repeatedly appear in more than one folktale and one folktale may carry more than one motif.

The supremacy of magic motifs in the local folktales regarding the applicability of the universal motif is not a wonder considering the nature of the folktales. They are narratives that have been passed down for many generations so long ago that it is impossible to identify the exact moment where it all began and its first narrators. Long ago predates the formation of Malaysia, magic reigned supreme among the Malay folks, and the complex system of magic touched on many aspects of life (Winstedt, 2007; Winzeler, 1983). Since folktale is not just fiction but a mirror of the phenomenon in the real world (Thompson, 1977/1946), the potent presence of magic motifs in the stories echoes the current practice of the Malays then. On the practice of many forms of magic among the Malays once, it is also apparent that the elements of magic abound in the Malay folklore (Skeat, 2018/1900) and this circumstance may too explain the dominance of the magic motifs.

In order to take the discussion a step further, it is revealed that the universal motifs are unsuccessful in being applied to some of the segments identified as motifs in the folktales analysed. Such motifs identified had to be applied to a more general universal sub-motifs and the class Z. Miscellaneous Groups of Motifs. For example, in some of the folktales, Sang Kancil or the mousedeer is the significant actor which justified it to be coded as the motif. Sang Kancil appears in many Malay folktales as one of the famous clever animal heroes that employ trickery and wisdom to outwit its enemies. It is a culture hero that becomes the meaningful expression of cleverness and wisdom in the Malay society (Peow, 2016). Nevertheless, the universal motif-index does not explicitly contain a sub-motif for the mousedeer but jackal and coyote (sub-motif J1117.1 Jackal as trickster and J1117.2 Coyote as trickster). Therefore, based on the nature of the Sang Kancil in the folktales, the study decided to code it to the sub-motifs of A521 Culture hero as dupe or trickster, J1100 Cleverness, J1117 Animal as trickster, W215 Extreme prudence, and finally Z200 Heroes.

The findings of the study infer that not all motifs and sub-motifs comprised in the original motifindex of folk literature are applicable when used as the analysis tool on the local folktales. The substantial reduction occurred based on the number of motifs and sub-motifs applied to the local folktale data. It is fair considering that folktale as part of folklore, mirrors a culture that gave birth to it since time was new and the European (which constituted of vast states) and Malaysian indeed bear distinct yet valuable cultures. The study not only helps to understand the ability of the universal motifs' transference and migration across cultures but in a way, it readies a tool of motif analysis particularly for the local folktales (Malay in the scope of this study). The said reduction of the universal motifs left the motif-index with the motifs and sub- motifs applicable to the local folktales. Besides, the methodology utilised in the study becomes an avenue toward a replication by similar future studies with different folktale data. Moreover, the knowledge gained that the magic motifs are dominant in the local folktales paves the way for the scholars of similar interest to better understand the nature of the local folktales' narrative content.

Nevertheless, the study is not liberated from limitation and challenge. As discussed above, some of the motifs identified from the local folktales analysed could not be coded precisely to the original motif-index of folk literature. As a result, they had to be applied to a more general universal sub-motifs and the class of Z. Miscellaneous Groups of Motifs. Such situation cripples the study from obtaining an accurate representation of the local folktales' motifs. That said, given the qualitative nature of the study and the number of folktales had to be analysed, it was a challenge and a monumental task to 
identify the motifs in the folktales then code them to the appropriate motifs or sub-motifs from the original motif-index of folk literature. Nevertheless, the task was relatively facilitated with the use of Atlas.ti to contain and employ all the folktale data and analysis. The CAQDAS allows the study to perform a systematic and transparent analysis flexibly and rapidly. The ensuing section presents the swan song of the article.

\section{Conclusion}

The present study was triggered by the curiosity to understand the applicability of the original motif-index of folk literature in the local folktales' context. The findings satiated the curiosity and led the study to understand that in applying the universal motifs of the motif-index of folk literature, some substantial reduction occurred due to the differences in both the European and Malaysian cultures. It also understood that out of the 22 motif classes, the D. Magic class is dominant. The motifs obtained, though reduced, are significant as it can function as the motif analysis tool for subsequent studies that involve local folktale data. It is acknowledged that based on the limitation stated, the motifs obtained do not accurately represent the local folktales considering the lack of local's culture-specific motifs in the original motif-index of folk literature. Therefore, such limitation will be overcome in the future by inventing and adding more culture-specific motifs to the existing local motifs established in the current study.

\section{References}

Bascom, W. (1965). The forms of folklore: Prose narratives. The Journal of American Folklore, 78(307), 3-20. doi:10.2307/538099

Baughman, E. W. (1966). Type and motif-index of the folktales of England and North America, 20. Bloomington, IN: Walter de Gruyter.

El-Shamy, H. M. (1995a). Folk traditions of the Arab world: A guide to motif classification, 1, Bloomington, IN: Indiana University Press.

El-Shamy, H. M. (1995b). Folk traditions of the Arab world: A guide to motif classification, 2, Bloomington, IN: Indiana University Press.

El-Shamy, H. M. (2006). A motif index of the thousand and one nights. Bloomington, IN: Indiana University Press.

Friese, S. (2019). Qualitative data analysis with ATLAS.ti (3rd ed.). Thousand Oaks, CA: Sage Publications.

Goldberg, H. (1998). Motif-index of Medieval Spanish folk narratives, 162. Tempe, AZ: Renaissance Tapes.

Hwang, S. (2008). Utilizing qualitative data analysis software: A review of Atlas.ti. Social Science Computer Review, 26(4), 519-527. doi:10.1177/0894439307312485

Jason, H. (2000). Motif, type, and genre: A manual for compilation of indices and a bibliography of indices and indexing. In L. Honko (Ed.), FF communications, 273. Suomi, Finland: Academia Scientiarum Fennica.

Krippendorff, K. (2013). Content analysis: An introduction to its methodology (3rd ed.). Thousand Oaks, CA: Sage Publications.

Kuckartz, U. (2014). Qualitative text analysis: A guide to methods, practice and using smartsoftware. 
Thousand Oaks, CA: Sage.

Laas, P. (2011). Preserving the national heritage: Audiovisual collections in Iceland. Libri, 61(2), 131142. doi:10.1515/libr.2011.011a

Lwin, S. M. (2010). Narrative structures in Burmese folk tales. Amherst, NY: Cambria Press.

Miles, M., Huberman, M., \& Saldana, J. (2014). Qualitative data analysis: A methods sourcebook (3rd ed.). Thousand Oaks, CA: SAGE Publications, Inc.

Neugaard, E. J. (1993). Motif-index of medieval Catalan folktales, 96, Binghamton, NY: Medieval \& Renaissance Texts \& Studies.

Neuland, L. (1981). Motif-index of Latvian folktales and legends, 97, Helsinki, Finland: Academia Scientiarum Fennica.

Peow, S. H. (2016). A comparative study of Malay and Chinese trickster tales: Sang kancil, the rabbit and the rat. Kajian Malaysia, 34(2), 59-73. doi: http://dx.doi.org/10.21315/km2016.34.2.3

Propp, V. (1998). Morphology of the folktale (14th ed.). Austin, TX: University of Texas Press. Schreier, M. (2012). Qualitative content analysis in practice (1st ed.). Thousand Oaks, CA: Sage Publications.

Schreier, M. (2013). Qualitative content analysis. In F. Uwe (Ed.), The SAGE handbook of qualitative data analysis (pp. 171-183). Thousand Oaks, CA: SAGE Publications Ltd.

Skeat, W. W. (2018). Malay magic: Being an introduction to the folklore and popular religion of the Malay Peninsula. New York, NY: Franklin Classics. (Original work published 1900)

Thompson, S. (1966). Motif-index of folk-literature, Vol. 1-6, Morton St. Bloomington: Indiana University Press.

Thompson, S. (1977). The folktale. Los Angeles, CA: University of Californi Press. (Original work published 1946)

Whyte, G., \& Classen, S. (2012). Using storytelling to elicit tacit knowledge from SMEs. Journal of Knowledge Management, 16(6), 950-962. doi:10.1108/13673271211276218

Winstedt, R. O. (2007). Shaman, saiva and sufi: A study of the evolution of Malay magic. Lexington, KY: Forgotten Books.

Winzeler, R. L. (1983). The study of Malay magic. Bijdragen tot de taal-, land-en volkenkunde (4), 435-458.

\section{AUTHOR BIODATA}

Harryizman Harun is a senior lecturer at the Department of Multimedia Technology, School of Multimedia Technology and Communication, College of Arts and Sciences, Universiti Utara Malaysia, Malaysia. He has been lecturing and researching since 2004. His research interest is folk literature and the application of multimedia in safeguarding the folk literature. Email: harry@uum.edu.my

Azliza Othman is a Senior Lecturer at the School of Multimedia Technology and Communication, Universiti Utara Malaysia. Her research interest include persuasive technology, multimedia learning, human computer interaction, user interface and children safety. She can be reached at azliza@uum.edu.my

Subashini Annamalai is a senior lecturer at the School of Multimedia Technology and Communication, Universiti Utara Malaysia. She has hybrid experience in information technology and multimedia and has been in the education field for more than 15 years. She has published articles in many Scopus journals in the area of her expertise. Her research interest includes (but not limited to) instructional multimedia, game development and human computer interaction. Email: subashini@uum.edu.my. 